\title{
Calcified pituitary concretions in the newborn
}

\author{
A. J. BARSON AND J. SYMONDS
}

From the Department of Pathology, University of Manchester

SUMMARY Anterior pituitary glands from 200 fetuses and infants ranging in age from 22 weeks' gestation to one year of life were examined histologically for the presence of concretions. Characteristically these are round, lamellated bodies, often strongly basophilic, containing phosphates and measuring between $10 \mu \mathrm{m}$ and $70 \mu \mathrm{m}$ in diameter. They decreased in incidence postnatally and were rarely seen 6 months after birth. It is suggested that these concretions are a degenerative change in cells subject to the vigorous secretory activity that is part of the normal physiology of the anterior lobe of the pituitary from mid-gestation.

During the routine histological examination of tissues from infants dying predominantly in the perinatal period it was noticed that a high proportion of the anterior pituitaries contained microscopical concretions which were often calcified. These lesions are not a usual feature of the adult anterior pituitary gland. Their high incidence in infancy and uniform morphology makes it impossible to attribute them to the known rare causes of intracranial calcification. Study of these lesions indicates that they are not pathological in origin but are part of the normal structure of the infant anterior pituitary, bearing in mind that 'normality' in these circumstances has to be based of necessity on the examination of pituitaries from patients who have died from natural disease. The phenomenon is not described in accounts of the normal embryological development of the pituitary gland (Atwell, 1926; Covell, 1927; Tilney, 1936; Falin, 1961). The only clear description in the literature that could be traced is over 30 years old (Plaut and Galenson, 1944).

\section{Materials and methods}

The study was based on the histological examination of 200 anterior pituitary glands obtained during routine necropsy. The majority of these were derived from perinatal deaths in St. Mary's Hospital, Manchester. 40 glands were removed from fresh stillbirths of between 22 and 42 weeks' gestation. The remaining 160 came from liveborn infants surviving up to one postnatal year. In addition 12 normal adult pituitary glands and 15 biopsies of adult pituitary adenomas were included.

A single haematoxylin and eosin (H \& E) sagittal

Received 30 December 1976 section through the whole anterior lobe of the pituitary gland was examined in each case. A von Kossa stain was prepared on $\mathbf{5 3}$ glands in the series. The case notes of all the patients were assessed with particular regard to gestational and postnatal age, maternal disease, and necropsy diagnosis.

\section{Results}

The concretions were round or ovoid, or occasionally pyramidal or elongated, and ranged from $10 \mu \mathrm{m}$ to $70 \mu \mathrm{m}$ in diameter. The majority had an irregular concentric laminated appearance, the laminae staining deep blue with haematoxylin and black with von Kossa's stain for phosphates (Fig. 1). Other concretions, while having the same overall form and size, had a sharply defined basophilic periphery with a homogeneous faintly eosinophilic interior (Fig. 2). No cellular reaction was seen in the vicinity of the concretions nor were they consistently located in proximity to a vessel or particular cell type or in any one region of the pars anterior. They were occasionally seen in the pars intermedia but never within the posterior lobe.

Relating the presence or absence of these concretions to the age of the patient (Table 1; Fig. 3) there is a peak incidence among neonatal deaths with no positives seen after 6 months of age. The 12 controls showed no concretions, though inquiry among colleagues did produce a single example of identical concretions in an adult pituitary, occurring in a woman of 82 dying in congestive heart failure with myxoedema. Examination of biopsies from 15 pituitary adenomas showed calcified concretions of different morphology in 3.

The proportion of concretions which were strongly 
Table 1 Incidence of pituitary concretions and their relauionship to age

\begin{tabular}{|c|c|c|c|c|c|c|c|c|c|}
\hline & \multirow{2}{*}{$\begin{array}{l}\text { Stillborn } \\
\begin{array}{l}22-42 \text { weeks } \\
\text { gestation } \\
(n=40)\end{array}\end{array}$} & \multicolumn{6}{|l|}{ Liveborn } & \multicolumn{2}{|l|}{ Adult } \\
\hline & & $\begin{array}{l}<1 w \\
(n=73)\end{array}$ & $\begin{array}{l}1-4 w \\
(n=27)\end{array}$ & $\begin{array}{l}1-2 m \\
(n=17)\end{array}$ & $\begin{array}{l}2-4 m \\
(n=18)\end{array}$ & $\begin{array}{l}4-6 m \\
(n=16)\end{array}$ & $\begin{array}{l}6-12 \\
(n=9)\end{array}$ & $\begin{array}{l}\text { Normal } \\
(n=12)\end{array}$ & $\begin{array}{l}\text { Pituitary } \\
\text { adenomas } \\
(n=15)\end{array}$ \\
\hline $\begin{array}{l}\text { Cases with } \\
\text { concretions }\end{array}$ & $21(52 \%)$ & $46(63 \%)$ & $17(63 \%)$ & $7(41 \%)$ & $4(24 \%)$ & $1(6 \%)$ & 0 & 0 & $3(20 \%)$ \\
\hline $\begin{array}{l}\text { Cases with strongly } \\
\text { basophilic concretions }\end{array}$ & $14(35 \%)$ & $20\left(27^{\circ}\right)$ & $4(15 \%)$ & $4(24 \%)$ & $2\left(12^{\circ}{ }_{v}^{\prime}\right)$ & $1\left(6^{\circ}{ }_{0}\right)$ & 0 & 0 & $3(20 \%)$ \\
\hline $\begin{array}{l}\text { Mean concretions } \\
\text { per section }\end{array}$ & $4 \cdot 7$ & $3 \cdot 4$ & $3 \cdot 0$ & $2 \cdot 9$ & $3 \cdot 5$ & $1 \cdot 0$ & 0 & & \\
\hline $\begin{array}{l}\text { Range of concretions } \\
\text { per section }\end{array}$ & $0-20$ & $0-17$ & $0-9$ & $0-8$ & $0-5$ & $0-1$ & 0 & & \\
\hline
\end{tabular}

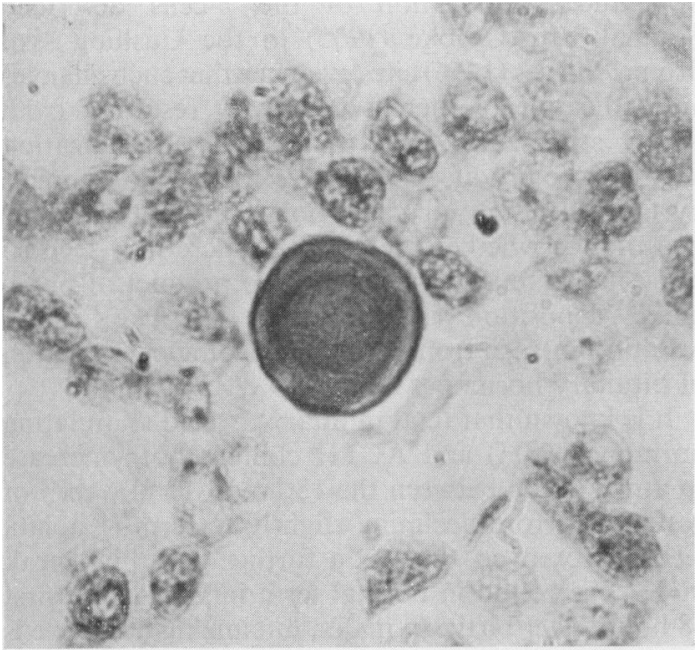

Fig. 1 Laminated pituitary concretion in a newborn infant. (von Kossa $\times 825$.)

haematoxophilic, and presumptively calcified, showed a similar decline in incidence to the sixth month. However, these strongly basophilic lesions accounted for a higher proportion of the glands from stillbirths than at any other age, even though concretions were commonest in the first postnatal month (Table 1; Fig. 3).

The numbers of concretions seen in any single section ranged from 0 to 20 on the $\mathrm{H} \& \mathrm{E}$ stained tissue from the stillbirths. This range decreased as postnatal age increased (Fig. 3), as did the average number of concretions seen per section with the exception of the 2- to 4-month age group (Table 1).

Von Kossa stains were performed on 53 infants, of whom 15 had strongly basophilic concretions on the $\mathrm{H} \& \mathrm{E}$ stain, 14 had weakly basophilic lesions, and 24 were apparently negative (Table 2). The great majority of the strongly basophilic concretions were von Kossa-positive, as were about $40 \%$ of those with a weak affinity for haematoxylin. Surprisingly, the von Kossa showed concretions in half

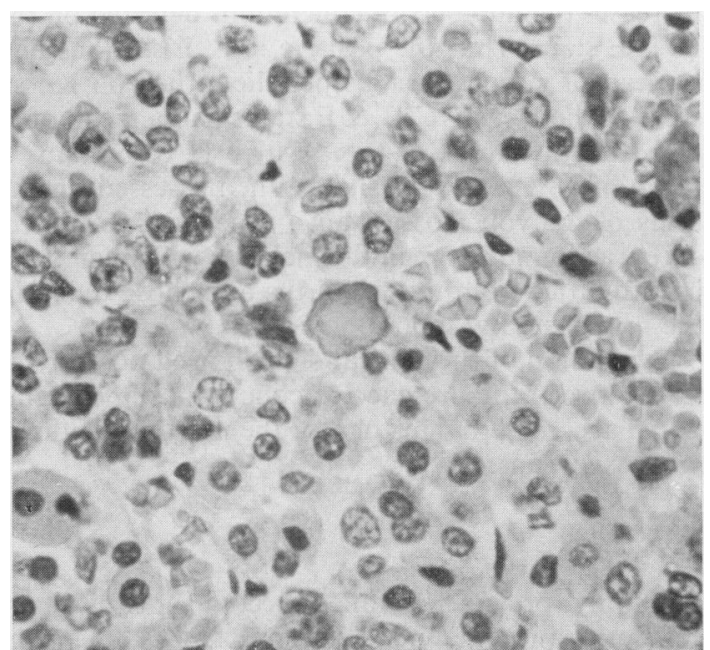

Fig. 2 Pituitary concretion with a strongly haematoxophilic outline and eosinophilic interior. ( $H$ and $E \times 400$.)

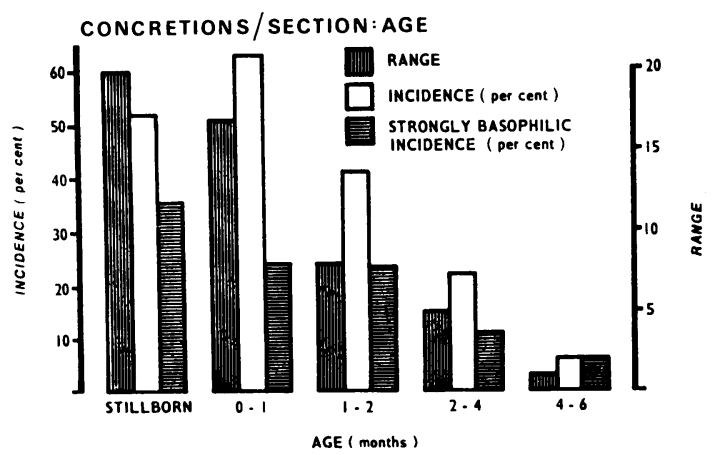

Fig. 3 Range in number of concretions seen per section, percentage incidence of sections with concretions, and percentage incidence of sections with concretions showing strong basophilia plotted against age. 
Table 2 Comparison of haematoxylin and eosin affinity of pituitary concretions with von Kossa staining reaction

\begin{tabular}{llcc}
\hline & No. of & & \\
& cases & Von Kossa-positive & Von Kossa-negative \\
\hline Negative H \& E & 24 & $12(50 \%)$ & $12(50 \%)$ \\
Positive H \& E & 29 & $20(63 \%)$ & $9(27 \%)$ \\
Strongly basophilic & 15 & $14(93 \%)$ & $1(7 \%)$ \\
Weakly basophilic & 14 & $6(43 \%)$ & $8(57 \%)$ \\
Total & 53 & 32 & 21 \\
\hline
\end{tabular}

the sections on which the $\mathrm{H} \& \mathrm{E}$ stain had apparently failed to show them. A corollary is that the von Kossa increases the numbers of concretions detected on the $H \& E$ stain. Thus the positive $H \& E$ sections had a mean of about 5 lesions per slide, the von Kossa stain of the 'negative' $H \&$ E stains had a mean of 6 , and the von Kossa of the positive $H \& E$ stains a mean of 18 lesions per slide. When assessed on the basis of the von Kossa stains, no significant difference was found between the incidence of concretions in pituitaries from the stillbirths and those dying in the first postnatal month.

Evaluation of the clinical data showed no correlation between the presence of concretions and gestational age, maternal history, or the necropsy findings in other organs.

\section{Discussion}

The only previous detailed account of pituitary concretions (Plaut and Galenson, 1944) differed in approach to the our study. In the former investigation 10 sections were examined from each of 150 infant pituitaries. The concretions were noted to reduce in incidence with age but the rate of this decline was not specifically plotted. The effect of von Kossa stains was not described, and doubt was expressed as to the presence of calcification on the grounds that some concretions were hard in consistency but without the deep haematoxophilia characteristic of calcified tissue. Our study showed numerous von Kossa-positive concretions which were overlooked on the $\mathrm{H} \& \mathrm{E}$ stain because of inability to absorb haematoxylin. It is evident from both studies that the more diligently these concretions are sought, either by appropriate stains or the number of sections per case examined, the more likely is their presence in any one individual likely to be detected. By examining 10 sections per gland, Plaut and Galenson showed the presence of concretions in all newborn infants, as opposed to $63 \%$ from examining single sections in the present series.

The main interest in these concretions lies in their aetiology. Their high incidence from midgestation, declining rapidly after the neonatal period to become a rarity after 6 months of age suggests that the concretions are a feature of the normal pituitary whose physiology differs in some way in the fetus and newborn to that necessary in later life. The morphology of these concretions strongly suggests deposition of calcium phosphates within individual cells of the anterior pituitary. The lamination evident in some concretions is often bilaminar as though there has been a relative sparing of the calcification within the cytoplasm of the secretory cell between the periphery of the nucleus and the outer cell membrane (Fig. 1). The appearances are reminiscent of, but not identical to, the degranulation and hyalinization of the $\beta$-cells described originally by Crooke (1935) in the Cushing syndrome. Purves (1966) cites evidence that such changes are indicative of increased activity resulting from strong stimulation, and that similar hyalinization may also be produced in some experimental animals by thyroidectomy or castration. This provokes the question of whether the calcific concretions seen so often in the fetal pituitary are the product of phosphate deposition in hyalinized 'Crooke's cells' resulting in turn from a high physiological secretion of pituitary hormones in utero.

It is known that fetal pituitary thyroid stimulating hormone (TSH) and ACTH content both increase to a maximum between the 18th and 22nd weeks of gestation before declining slightly to term (Kaplan, 1972). Moreover, there is a further very high peak in TSH secretion in normal term infants in the first 48 hours after birth. In males, luteinizing hormone is maximal in pituitaries between 24 and 28 weeks, while follicle stimulating hormone in females is greatest between 22 and 31 weeks' gestation. An attractive inference is that this very vigorous secretory activity of the fetal anterior pituitary is related to the phenomenon of the presence of calcified concretions over the subsequent six months of life. This belief is supported by the finding that $20 \%$ of the pituitary adenomas had similar (but not identical) concretions and that the single other adult gland with these lesions occurred in a woman dying with myxoedema secondary to Hashimoto's thyroiditis.

Finally, it may be observed that intrauterine endocrine activity is not the only factor in inducing calcification in the newborn. Focal calcification of soft tissues is seen far more frequently in the fetus than in the child or adult. Such calcification occurs in a wide variety of pathological conditions in utero which result in cell death (Potter and Craig, 1975). Pituitary calcification seen in the newborn may occur consequent to physiological cell death in utero which is an essential aspect of maturation. The susceptibility of fetal cells to calcification is due in part to intrinsic factors which are not peculiar to pituitary tissue or any one cause of cell death. 


\section{References}

Atwell, W. J. (1926). The development of the hypophysis cerebri in man with special reference to the pars tuberalis. American Journal of Anatomy, 37, 159-193.

Covell, W. P. (1927). Growth of the human prenatal hypophysis and the hypophyseal fossa. American Journal of Anatomy, 38, 379-422.

Crooke, A. C. (1935). A change in the basophil cells of the pituitary gland common to conditions which exhibit the syndrome attributed to basophil adenoma. Journal of Pathology and Bacteriology, 41, 339-349.

Falin, L. I. (1961). The development of human hypophysis and differentiation of cells of its anterior lobe during embryonic life. Acta Antomica, 44, 188-205.

Kaplan, S. A. (1972). Disorders of the endocrine system. Pathophysiology of Gestational Disorders, p. 105. Ed. by N. S. Assali. Academic Press, New York.
Plaut, A., and Galenson, E. (1944). Concretions in the anterior pituitary lobe of the human embryo and the newborn. American Journal of Pathology, 20, 223-230.

Potter, E. L., and Craig, J. M. (1975). Pathology of the Fetus and the Infant, 3rd ed., p. 618. Lloyd-Luke, London.

Purves, H. D. (1966) Cytology of the adenohypophysis. The Pituitary Gland, Vol. I Chap. 4. Ed. by G. W. Harris and B. T. Donovan. Butterworths, London.

Tilney, F. (1936). The development and constituents of the human hypophysis. Bulletin of the Neurological Institute of New York, 5, 387-436.

Correspondence to Dr. A. J. Barson, Department of Pathology, The Medical School, Oxford Road, Manchester M13 9PT. 